\title{
PERENCANAAN DINDING PENAHAN TANAH TIPE GRAVITASI DAN TIPE KANTILEVER PADA GRAVING DOCK DI PT DOK DAN PERKAPALAN AIR KANTUNG UNIT GALANGAN SELINDUNG KOTA PANGKALPINANG
}

\author{
Syarifullah \\ Alumni Teknik Sipil Universitas Bangka Belitung \\ Email : Syarifullah100@gmail.com \\ Ferra Fahriani \\ Dosen Teknik Sipil Universitas Bangka Belitung \\ Email :f2_ferra@yahoo.com \\ Yayuk Apriyanti \\ Dosen Teknik Sipil Universitas Bangka Belitung \\ Email : yayukapriyanti26@gmail.com
}

\begin{abstract}
ABSTRAK
Graving dock merupakan fasilitas pengedokan kapal yang mempunyai bentuk seperti kolam yang terletak di tepi pantai atau sungai.Pada pnelitian ini dilakukan analisis graving dock di di PT Dock dan Perkapalan Air Kantung Unit Galangan Selindung Kota Pangkalpinang. Studi ini bertujuan untuk merencanakan dimensi dinding penahan tanah yang stabil terhadap stabilitas penggeseran, penggulingan, daya dukung tanah serta penurunannya dengan menggunakan tipe gravitasi dan tipe kantilever pada graving dock. Perhitungan tekanan tanah dihitung dengan menggunakan Teori Rankine dan coulomb serta perhitungan stabilitas terhadap keruntuhan kapasitas dukung tanah dihitung berdasarkan persamaan Hansen dan Vesic berdasarkan datadata karakteristik keteknikan (c dan Ø). Hasil perhitungan untuk dinding gravitasi dengan material dinding dari pasangan batu direncanakan tinggi dinding $(H)=6 \mathrm{~m}$, Lebar alas dinding $(B 1)=4,2 \mathrm{~m}$, Lebar atas dinding $(B 2)=0,5 \mathrm{~m}$, Tebal alas pondasi $(D)=1 \mathrm{~m}$, dan Lebar alas depan dinding $(B 3)=0,5 \mathrm{~m}$, didapatkan faktor keamanan terhadap geser $(F g s)=4,64$,faktor keamanan terhadap guling $(\mathrm{Fgl})=4,1$ faktor keamanan terhadap keruntuhan daya dukung tanah $(F)=4,82$ dan stablitas terhadap penurunan $\left(\sum S\right)=5,15$ $\mathrm{mm}$.Sedangkan dinding kantilever dengan material dinding dari pasangan beton direncanakan tinggi dinding $(H)=6 \mathrm{~m}$, Lebar alas dinding $(B 1)=4,2 \mathrm{~m}$, Lebar atas dinding $(B 2)=0,4 \mathrm{~m}$, Tebal alas pondasi $(D)=0,6 \mathrm{~m}$, dan Lebar alas depan dinding (B3) $=1,4 \mathrm{~m}$, didapatkan stabilitas faktor keamanan terhadap geser (Fgs) 2,75, faktor keamanan terhadap guling $(\mathrm{Fgl})=2,53$, faktor keamanan terhadap keruntuhan daya dukung tanah $(F)=4,15$ dan stablitas terhadap penurunan $(\Sigma S)=0,56 \mathrm{~mm}$
\end{abstract}

Kata kunci : Dinding penahan tanah, dimensi, galangan kapal.

\section{PENDAHULUAN}

\section{Latar Belakang}

Salah satu dari jenis galangan kapal (tempat untuk membangun dan memperbaiki kapal yang terletak di tepi laut atau sungai) adalah graving dock.
Graving dock merupakan fasilitas pengedokan kapal yang mempunyai bentuk seperti kolam yang terletak di tepi pantai atau sungai. Daerah di sekitar graving dock pada penelitian ini terletak pada tanah lunak. Tanah lunak memeliki 
kekuatan yang rendah terhadap stabilitas bangunan. Maka untuk itu dibutuhkan sebuah kontruksi bangunan dinding penahan tanah yang lebih kuat sehingga mampu menahan beban-beban yang bekerja pada kondisi tanah tersebut. Pada penelitian ini dianalisis dinding penahan tanah yang berupa perkuatan beton menggunakan tipe gravitasi dan tipe kantilever

Dari segi kekuatan dinding penahan tanah harus memenuhi beberapa unsur keamanan yang harus ada diantaranya stabilitas pergeseran, penggulingan, daya dukung serta penurunannya. Oleh karena itu dilakukan analisis stabilitas banguan dari kedua tipe dinding penahan tanah yang didesain selanjutnya akan dibandingkan tipe yang memilki kekuatan keamanan yang terbesar.

\section{LANDASAN TEORI}

Dalam meninjau kestabilan Dinding Penahan Tanah , perlu memperhatikan hal-hal berikut :

1) Faktor aman terhadap pergeseran dan penggulingan harus mencukupi

2) Tekanan yang terjadi pada tanah dasar pondasi harus tidak boleh melebihi

kapasitas dukung ijin

3) Stabilitas lereng secara keseluruhan harus memenuhi syarat

Selain itu, jika tanah dasar mudah mampat, penurunan tak seragam yang terjadi harus tidak boleh berlebihan.

\section{Kestabilan Terhadapan Geser}

Faktor aman terhadap penggeseran dasar pondasi (Fgs) minimum, diambil 1,5. Bowles 1997 menyarankan :

Fgs $\geq 1,5$ untuk tanah dasar granular

Fgs $\geq 2$ untuk tanah dasar kohesif
Gaya-gaya yang menggeser dinding penahan tanah akan ditahan oleh :

1) Gesekan antara tanah dengan dasar pondasi.

2) Tekan tanah pasif bila di depan dinding penahan terdapat tanah timbunan.

Faktor aman terhadap penggeseran (Fgs), didefinisikan sebagai:

$$
F g s=\frac{\sum R h}{\sum P h} \geq 1,5
$$

- untuk tanah granular $(\mathrm{c}=0)$ :

$$
\begin{aligned}
\sum \mathrm{Rh} & =\mathrm{W} . \mathrm{f} \\
& =\mathrm{W} . \mathrm{Tg} \delta \mathrm{b} ; \text { dengan } \delta \mathrm{b} \leq \varphi
\end{aligned}
$$

- untuk tanah kohesif $(\varphi=0)$ :

$\sum \mathrm{Rh}=\mathrm{Ca} . \mathrm{B}$

- untuk tanah c- $\varphi(\varphi>0$ dan $\mathrm{c}>0)$

$\sum \mathrm{Rh}=\mathrm{Ca} \cdot \mathrm{B}+\mathrm{W} \operatorname{tg} \delta b$

Dengan :

$\sum \mathrm{Rh}=$ tahanan dinding penahan tanah terhadap penggeseran

$\mathrm{W}=$ berat total dinding penahan dan tanah di atas pelat pondasi $(\mathrm{kN})$

$\delta \mathrm{b} \quad=$ sudut gesekan antara tanah dan dasr pondasi biasanya diambil $1 / 3-(2 / 3)$ $\varphi$

$\mathrm{Ca}=\operatorname{ad} \times \mathrm{c}=$ adhesi anatara tanah dan dasar dinding $\left(\mathrm{kN} / \mathrm{m}^{2}\right)$

$\mathrm{C}=$ kohesi tanah dasar $\left(\mathrm{kN} / \mathrm{m}^{2}\right)$

ad $\quad=$ faktor adhesi

$\mathrm{B}=$ lebar pondasi $(\mathrm{m})$

$\sum \mathrm{Ph}=$ jumlah gaya-gaya horizontal $(\mathrm{kN})$

$\mathrm{F} \quad=\operatorname{tg} \delta \mathrm{b}=$ koefisien gesek antara tanah dasar dan dasar pondasi 
Faktor aman terhadap penggeseran dasar pondasi (Fgs) minimum, diambil 1,5.

Bowles 1997 menyarankan :

Fgs $\geq 1,5$ untuk tanah dasar granular

Fgs $\geq 2$ untuk tanah dasar kohesif

\section{Kestabilan Terhadap Guling}

Faktor aman akibat terhadap penggulingan $(\mathrm{Fgl}), \quad$ didefinisikan sebagai:

$F g l=\frac{\sum M w}{\sum M g l}$

$\sum \mathrm{Mw}=\mathrm{W} \cdot \mathrm{b} 1$

$\sum \mathrm{Mgl}=\sum$ Pah. h1 $+\sum$ Pav. B

$\sum \mathrm{Mw}=$ momen yang melawan penggulingan (kN.m)

$\sum \mathrm{Mgl}=$ momen yang mengakibatkan penggulingan (kN.m)

$\mathrm{W}=$ berat tanah di atas pelat fondasi + berat sendiri dinding penahan $(\mathrm{kN})$

$\mathrm{B}=$ lebar kaki dinding penahan $(\mathrm{m})$

$\sum$ Pah $=$ jumlah gaya-gaya horizontal $(\mathrm{kN})$

$\sum$ Pav = jumlah gaya-gaya vertikal $(\mathrm{kN})$

Faktor aman terhadap penggulingan $(\mathrm{Fgl})$

bergantung pada jenis tanah, yaitu :

$\mathrm{Fgl} \geq 1,5$ untuk tanah dasar granuler

$\mathrm{Fgl} \geq 2$ untuk tanah dasar kohesif

\section{Stabilitas Terhadap Keruntuhan Kapasitas Dukung Tanah menggunakan Persamaan Hansen (1970) dan Vesic (1975)}

Kapasitas dukung ultimit dihitung dengan menggunakan persamaan Hansen(1970) dan Vesic (1975) untuk beban miring dan eksentris:

$\mathrm{qu}=$ dc.ic.c.Nc + dq.iq.Df. $\gamma \cdot \mathrm{Nq}+$ $\mathrm{d} \gamma . \mathrm{i} \gamma .0,5 . \mathrm{B} \gamma . \mathrm{N} \gamma$

dengan,

$\mathrm{dc}, \mathrm{dq}, \mathrm{d} \gamma \quad=$ faktor kedalaman

ic,iq,i $\quad=$ faktor kemiringan beban

$\mathrm{B} \quad=$ lebar dasar fondasi

sebenarnya $(\mathrm{m})$

$$
\begin{array}{ll}
\mathrm{e} & =\text { eksentrisitas beban }(\mathrm{m}) \\
\gamma & =\text { berat volume tanah } \\
\left(\mathrm{kN} / \mathrm{m}^{3}\right) & \\
\begin{array}{l}
\mathrm{Nc}, \mathrm{Nq}, \mathrm{N} \gamma \\
\text { dukung }
\end{array} & =\text { faktor-faktor kapasitas }
\end{array}
$$

Penurunan Segera pada Fondasi Empat Persegi Panjang Fleksibel

Penurunan segera pada sudut dari beban berbentuk luasan empat persegi panjang fleksibel dinyatakan oleh persamaan :

$$
S i=\frac{q_{n} B}{E}\left(1-\mu^{2}\right) I p
$$

Dengan,

$$
\begin{array}{ll}
\mathrm{B} & =\text { lebar area pembebanan }(\mathrm{m}) \\
\mathrm{Ip} & =\text { koefisien pengaruh } \\
\mu & =\text { rasio poisson } \\
\mathrm{q}_{\mathrm{n}} & =\text { tambahan tegangan }\left(\mathrm{kN} / \mathrm{m}^{2}\right)
\end{array}
$$

\section{Penurunan Konsolidasi}

Penurunan akibat konsolidasi primer dinyatakan oleh persamaan-persaman berikut ini :

$$
S c=\frac{\Delta e}{1+e_{o}} H
$$

Untuk lempung normally consolidated,

$$
S c=\frac{C c}{1+e_{o}} H \log \frac{P o^{\prime}+\Delta P}{P o^{\prime}}
$$

Untuk lempung overconsolidated, harus dipertimbangkan pada dua kondisi, yaitu

a Jika $P_{1}^{\prime}<P_{c}$,

$S c=\frac{C r}{1+e_{o}} H \log \frac{P o^{\prime}+\Delta P}{P o^{\prime}}$

Dengan

$P o+\Delta P=P_{1}$ '

$\Delta P=\frac{1}{6}(\Delta P a+4 \Delta P t+\Delta P b)$

$\Delta \mathrm{P}=$ tambahan tegangan efektif setelah beban bekerja

$\Delta \mathrm{Pa}=$ tambahan tegangan pada bagian atas lapisan 
$\Delta \mathrm{Pt}=$ tambahan tegangan pada bagian tengah lapisan

$\Delta \mathrm{Pb}=$ tambahan tegangan pada bagian bawah lapisan

b. Jika $P o^{\prime}<P_{c}{ }^{\prime}<P_{l}$,

$S c=\frac{C r}{1+e_{o}} H \log \frac{P o^{\prime}+\Delta P}{P o^{\prime}}+\frac{C c}{1+e_{o}} H \log \frac{P o^{\prime}+\Delta P}{P c^{\prime}}$

Total Penurunan

$\mathrm{S}=\mathrm{Si}+\mathrm{Sc}$

Dengan :

$\mathrm{S}=$ penurunan total

$\mathrm{Si}=$ penurunan segera

$\mathrm{Sc}=$ penurunan konsolidasi

\section{METODE PENELITIAN}

Penelitian ini dilakukan di PT Dok dan Perkapalan Air Kantung Galangan Selindung Kota Pangkalpinang Provinsi Kepulauan Bangka Belitung.

Tahapan penelitian dapat dilihat secara skematis dalam bentuk diagram alir sebagai berikut :

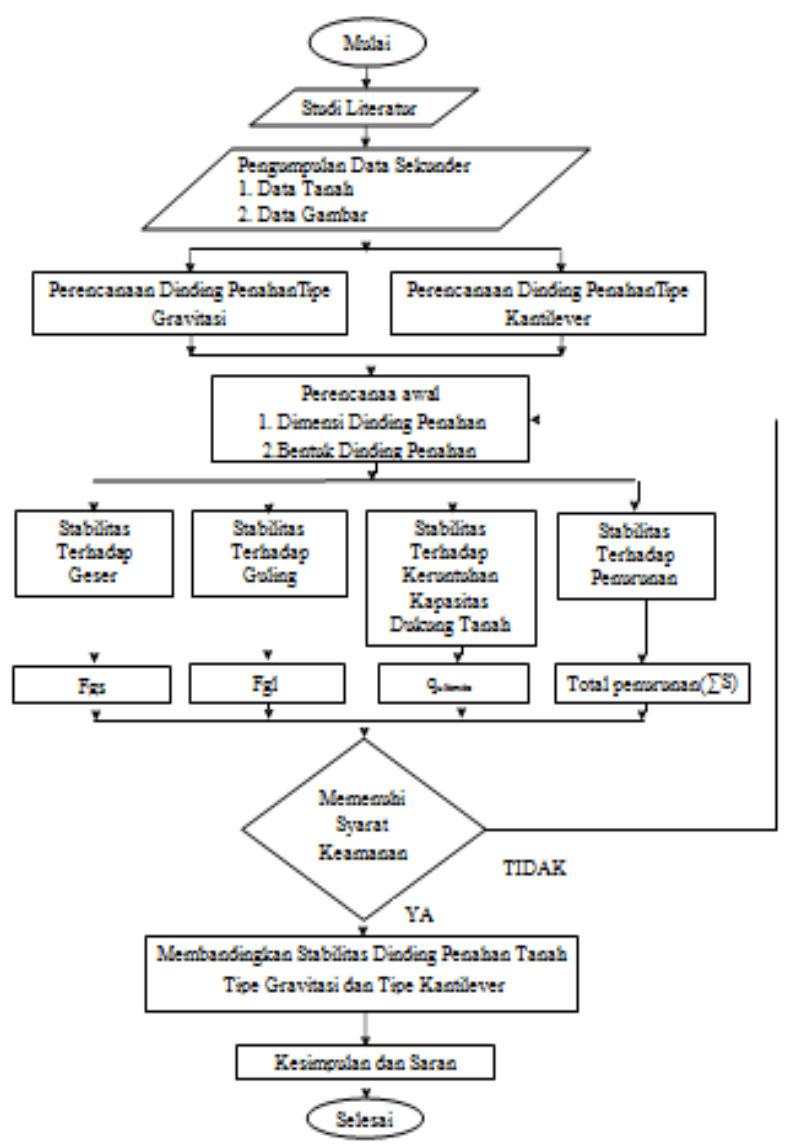

Tahap awal penelitian adalah melakukan studi literatur guna merencanakan analisis dan langkahlangkah yang akan dilaksanakan dalam penelitian. Perencanaan yang dipilih adalah perencanaan dinding penahan tanah dengan tipe gravitasi dan perencanaan dinding penahan tanah dengan tipe kantilever. Langkah selanjutnya yaitu perencanaan awal dinding penahan tanah yaitu dimensi dan bentuk dinding penahan tanah Tahapan berikutnya menghitung stabilitas terhadap penggeseran, guling keruntuhan kapasitas dukung tanah. Perhitungan stabilitas terhadap keruntuhan kapasitas dukung tanah dan penurunan. Selanjutnya dilakukan perbandingan nilai stabilitas antara dinding penahan tanah tipe gravitasi dan tipe kantilever yang memenuhi syarat keamanannya.

\section{HASIL DAN PEMBAHASAN}

\section{Data Penyelidikan Tanah}

Dalam penelitian ini digunakan data penyelidikan tanah seperti pada tabel 1

Tabel 1 Parameter Tanah

\begin{tabular}{|c|c|c|c|c|c|c|c|c|}
\hline \multirow[t]{2}{*}{ No } & $\begin{array}{c}\text { Kedalaman } \\
\text { Lapisan }\end{array}$ & \multirow[t]{2}{*}{$\begin{array}{l}\text { Tipe } \\
\text { Tanah }\end{array}$} & \multirow[t]{2}{*}{$\begin{array}{l}\text { Warna } \\
\text { Tanah }\end{array}$} & \multirow[t]{2}{*}{$\begin{array}{c}\text { Deskripsi } \\
\text { Tanah }\end{array}$} & \multirow{2}{*}{$\begin{array}{c}\text { Berat } \\
\text { Volume } \\
\text { Tanah }(\gamma \mathrm{n}) \\
\left(\mathrm{gr} / \mathrm{cm}^{3}\right) \\
\end{array}$} & \multirow{2}{*}{$\begin{array}{c}\text { Sudut } \\
\text { Geser } \\
(\varphi)^{\circ}\end{array}$} & $\begin{array}{l}\text { Kohesi } \\
\text { (C) }\end{array}$ & \multirow{2}{*}{$\frac{\gamma \mathrm{sat}}{\left(\mathrm{gr} / \mathrm{cm}^{3}\right)}$} \\
\hline & (m) & & & & & & $\left(\mathrm{kg} / \mathrm{cm}^{2}\right)$ & \\
\hline 1 & $0-1,5$ & $\begin{array}{l}\text { pasir } \\
\text { halus }\end{array}$ & $\begin{array}{c}\text { putih } \\
\text { kecoklatan }\end{array}$ & $\begin{array}{l}\text { agak } \\
\text { padat }\end{array}$ & 1,694 & 6,944 & 0,105 & \\
\hline 2 & $1,5-6$ & $\begin{array}{l}\text { pasir } \\
\text { halus }\end{array}$ & $\begin{array}{c}\text { putih } \\
\text { kecoklatan }\end{array}$ & $\begin{array}{l}\text { agak } \\
\text { padat }\end{array}$ & & 6,944 & 0,105 & 1,697 \\
\hline 3 & $6-12$ & $\begin{array}{l}\text { pasir } \\
\text { halus }\end{array}$ & $\begin{array}{c}\text { putih } \\
\text { kecoklatan }\end{array}$ & $\begin{array}{l}\text { agak } \\
\text { padat }\end{array}$ & & 6,944 & 0,105 & 1,697 \\
\hline 4 & $0-1$ & $\begin{array}{l}\text { pasir } \\
\text { halus }\end{array}$ & $\begin{array}{c}\text { putih } \\
\text { kecoklatan }\end{array}$ & $\begin{array}{l}\text { agak } \\
\text { padat }\end{array}$ & & 6,944 & 0,105 & 1,697 \\
\hline
\end{tabular}

Sumber PT Dok dan Perkapalan Air Kantung Galangan Selindung

Berdasarkan data pada tabel 1 didapatkan nilai Ka, Kp dan $\gamma$ Koefisien tekanan tanah aktif :

$$
\begin{aligned}
& K_{a}=\operatorname{tg}^{2}\left(45^{0}-\varphi / 2\right) \\
& K_{a}=\operatorname{tg}^{2}\left(45^{0}-6,944 / 2\right)
\end{aligned}
$$

Gambar 1 Diagram Alir 
$K_{a}=0,78$

Koefisien tekanan tanah pasif :

$K p=\operatorname{tg}^{2}\left(45^{0}+\varphi / 2\right)$

$K p=\operatorname{tg}^{2}\left(45^{0}+6,944 / 2\right)$

$K p=1,28$

$\gamma^{\prime}=\gamma s a t-\gamma w$

$\gamma^{\prime}=(1,697-1) \mathrm{gr} / \mathrm{cm}^{3}$

$\gamma^{\prime}=697 \mathrm{~kg} / \mathrm{m}^{2}$

\section{Perencanaan Dinding Penahan Tanah}

Perencanaan dinding penahan tanah membutuhkan data-data yang akurat dan pendukung untuk menghasilkan hasil perencanaan yang baik. Dinding Penahan Tanah berbentuk gravitasi merupakn dinding pasangan batu dengan $\gamma=2200$ $\mathrm{kg} / \mathrm{m}^{3}$, sedngakan dinding penahan tanah berbentuk kantilever merupakan didnding beton dengan $\gamma=2500 \mathrm{~kg} / \mathrm{m}^{3}$. Dimensi dinding penahan tanah yang dianalisis dalam penelitian ini dapat dilihat pada gambar 2 dan gambar 3

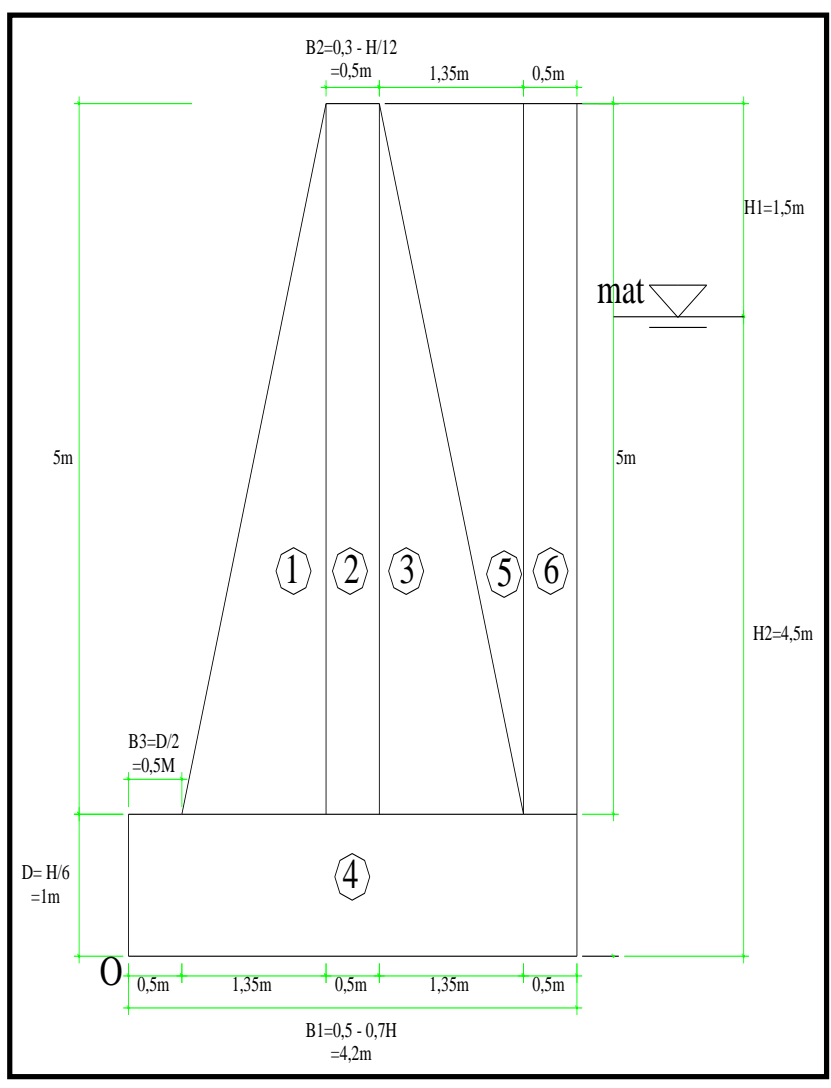

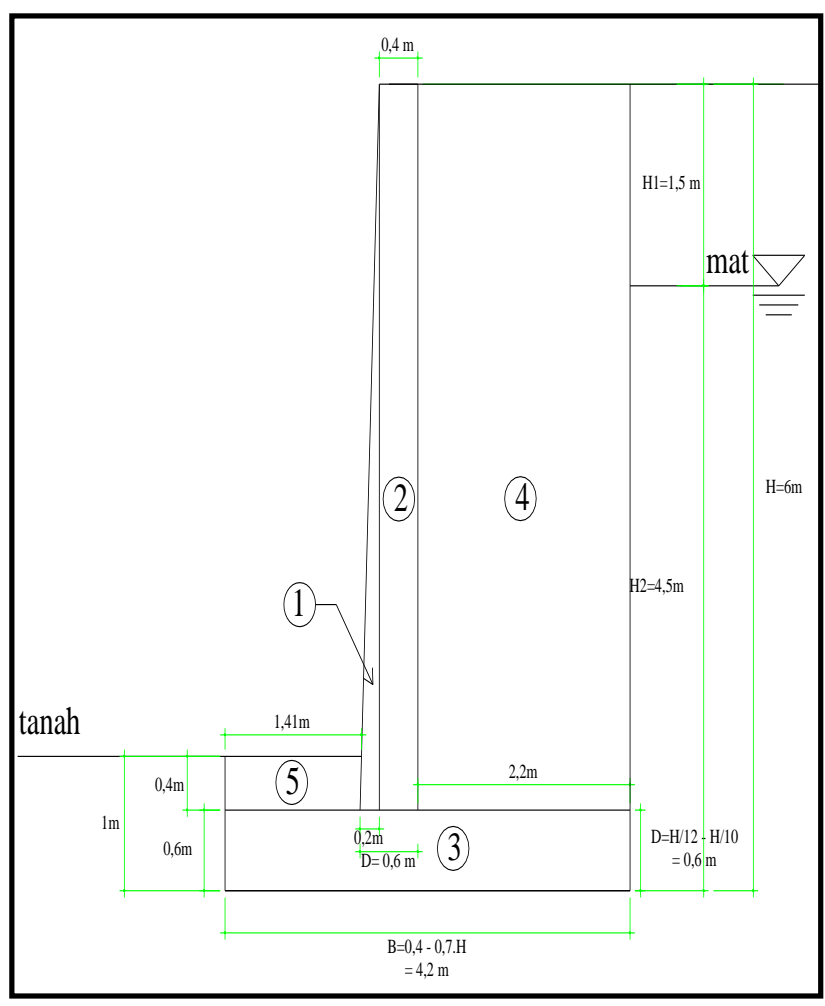

Gambar 3 Dimensi DPT Tipe Kantilever

\section{Analisis Kestabilan Dinding Penahan Tanah}

Berikut ini adalah tabel perbandingn hasil analisis stabilitas Dinding Penahan tanah pada kedua tipe, didapatkan faktor keamanan stabilitas terhadap geser $(F g s)$, stablitas terhadap guling $(F g l)$ dan stablitas terhadap keruntuhan kapasitas dukung tanah dan penurunan $\left(\sum \mathrm{S}\right)$

Tabel 2 Perbandingan Faktor Keamanan dan Penurunan DPT

\begin{tabular}{|l|c|c|c|c|}
\hline \multirow{2}{*}{ Tipe DPT } & \multicolumn{4}{|c|}{ Faktor Keamanan dan } \\
& Penurunan DPT & \multicolumn{2}{c|}{} \\
\cline { 2 - 5 } & Fgs & Fgl & F & $\sum$ S \\
\hline Dinding & 4,64 & 4,10 & 4,82 & $\begin{array}{c}5,15 \\
\mathrm{~mm}\end{array}$ \\
Gravitasi & & & & $\begin{array}{c}0,56 \\
\mathrm{~mm}\end{array}$ \\
\hline Dinding & 2,75 & 2,53 & 4,15 & \\
Kantilever & & & & \multicolumn{4}{|c|}{} \\
\hline
\end{tabular}

Gambar 2 Dimensi DPT Tipe Gravitasi 
Berdasarkan hasil analisis stabilitas Dinding Penahan tanah pada kedua tipe didpatkan faktor keamanan stabilitas terhadap geser $(F g s)$, stablitas terhadap guling $(F g l)$ dan stablitas terhadap keruntuhan kapasitas dukung tanah ( $\mathrm{q}_{\text {ultimite }}$ ) dan penurunan dinding tipe gravitasi memiliki nilai yang lebih besar dibandingkan dinding tipe kantilever.

\section{PENUTUP}

\section{Kesimpulan}

Berdasarkan perencanaan yang dilakukan, maka dapat disimpulkan sebagai berikut ini.

1. Desain Dinding Penahan Tanah yang memenuhi syarat keamanan yaitu :

a. Dinding Gravitasi

Berdasarkan hasil dari perhitungan maka untuk dinding gravitasi dengan material dinding dari pasangan batu direncanakan tinggi dinding $(\mathrm{H})=6 \mathrm{~m}$, Lebar alas dinding $(\mathrm{B} 1)=4,2 \mathrm{~m}$, Lebar atas dinding $(\mathrm{B} 2)=0,5 \mathrm{~m}$, Tebal alas pondasi $(\mathrm{D})=1 \mathrm{~m}$, dan Lebar alas depan dinding $(\mathrm{B} 3)=0,5 \mathrm{~m}$, didapatkan faktor keamanan terhadap geser $(\mathrm{Fgs})=4,64 \geq$ 1,5 , faktor keamanan terhadap guling $(\mathrm{Fgl})=4,1 \geq 1,5$, faktor keamanan terhadap keruntuhan daya dukung tanah (F) $=4,82 \geq 3$ dan stablitas terhadap penurunan $\left(\sum \mathrm{S}\right)=5,15 \mathrm{~mm} \leq 0,6 \mathrm{~cm}$

\section{b. Dinding Kantilever}

Berdasarkan hasil dari perhitungan maka untuk dinding kantilever dengan material dinding dari pasangan beton direncanakan tinggi dinding $(\mathrm{H})=6 \mathrm{~m}$, Lebar alas dinding $(\mathrm{B} 1)=4,2 \mathrm{~m}$, Lebar atas dinding $(\mathrm{B} 2)=0,4 \mathrm{~m}$, Tebal alas pondasi $(\mathrm{D})=0,6 \mathrm{~m}$, dan Lebar alas
Hal ini karena luasan dinding gravitasi yang lebih besar dibandingkan dinding kantilever menyebabkan gaya penahan untuk menahan gaya aktif tanah lebih besar dinding gravitasi daripada dinding kantilever, sehingga besar faktor keamanan yang terjadi pada dindig gravitasi menyebabkan nilai yang lebih besarpula.

depan dinding $(\mathrm{B} 3)=1,4 \mathrm{~m}$, didapatkan stabilitas faktor keamanan terhadap geser (Fgs) $2,75, \geq 1,5$, faktor keamanan terhadap guling $(\mathrm{Fgl})=2,53 \geq 1,5$, faktor keamanan terhadap keruntuhan daya dukung tanah $(\mathrm{F})=4,15 \geq 3$ dan stablitas terhadap penurunan $\left(\sum \mathrm{S}\right)=0,56 \mathrm{~mm} \leq$ $0,6 \mathrm{~cm}$.

2. Dari hasil analisis perhitungan yang telah dilakukan, didapatkan nilai faktor keamanan stabilitas terhadap geser $(F g s)$, stablitas terhadap guling $(F g l)$ dan stablitas terhadap keruntuhan kapasitas dukung tanah ( $\mathrm{q}_{\text {ultimite}}$ ) dan penurunan dinding tipe gravitasi memiliki nilai yang lebih besar dibandingkan dinding tipe kantilever.

Pada tipe kantilever stabilitas Dinding Penahan Tanah masih dalam batas aman dan penurunan yang terjadi kecil, sehingga tipe kantilever lebih efisien dalam penggunaannya.

\section{DAFTAR PUSTAKA}

Azizah, 2015, Perencanaan Tanggul dan Dinding Penahan Untuk Pengendalian Banjir di Sungai Cileungsi Kabupaten Bogor Jawa Barat. 
Bastomi, AY., 2015, Tugas Besar Rekayasa Fondasi II, UBB, Bangka.

Budi, GS,. 2011, Pondasi Dangkal, Jilid I, UGM, Yogyakarta

Cahya, WT,.2013, Perhitungan Struktur Dinding Penahan Tanah pada Pembangunan Longsoran pada Ruas Jalan Soekarno-Hatta Km 8 Balikpapan, Tugas Akhir, Fakultas Teknik, Univesitas 17 Agustus 1945 Samarinda, Samarinda.

Das, BM,. 1998, Mekanika Tanah, Jilid II, Terjemahan, Erlangga, Jakarta

Fahriani, F., 2015, Analisis Daya Dukung Tanah dan Penurunan Pondasi pada Daerah pesisir Pantai Utara Kabupaten Bangka.

Fiansyah, H,. 2016, Perencanaan Dinding Penahan Tanah pada Lapangan Olahraga UPTD Balai Pelatihan Kesehatan (BAPELKES) Samarinda.

Hakam, Abdul., 2011, Studi Stabilitas Dinding Penahan Tanah Kantilever pada Ruas Jalan Silaing Padang Bukittinggi Km 64 + 500, Jakarta.

Hardiatmo, H., 2010, Analisis dan Perancangan Fondasi II, Jilid II, Gadjah Mada Universty Press, Yogyakarta.

Hardiatmo, H., 2011, Analisis dan Perancangan Fondasi I, Jilid II,
Gadjah Mada Universty Press, Yogyakarta.

Hardiatmo, H., 2012, Mekanika Tanah, Jilid V, Gadjah Mada Universty Press, Yogyakarta.

Hardiatmo, H., 2012, Mekanika Tanah, Jilid VI, Gadjah Mada Universty Press, Yogyakarta.

Nugraha, A,. 2013, Perencanaan Dinding Penahan Tanah Dengan Menggunakan Program GEO5, Tugas Akhir, Fakultas Teknik, Universitas Muhammadiyah, Surakarta.

Nur, OF,. 2010, Analisa Stabilitas Dinding Penahan Tanah (Retaining Walls) Akibat Beban Dinamis dengan Simulasi Numerik.

Sunggono, 1995, Buku Teknik Sipil, Jilid I, Nova, Bandung.

Suryadi, dkk,. 2015 Analisis stabilitas pada tanah timbunan dengan perkuatan geotekstil dikombinasikan dengan dinding penahan tanah di ruas jalan tol cisumdawu.

Syafruddin, 2004, Desain Dinding Penahan Tanah (Retaining Walls) di Tanah Rawa pada Proyek Jalan.

Tjokorda, dkk., 2010, Analisis Stabilitas Lereng pada Badan Jalan dan Perencanaan Perkuatan Dinding Penahan Tanah, Yogyakart 